\title{
A patient with six primary carcinomata
}

\author{
GODFREY LA FERLA \\ F.R.C.S. \\ WILLIAM O. THOMSON* \\ F.R.C.S. \\ *Hairmyres Hospital and Department of Surgery, Stobhill Hospital, Glasgow
}

\begin{abstract}
Summary
We report a patient who developed six different primary carcinomata over a period of 3 years. These were of sigmoid colon, left breast, left kidney, right breast and two basal cell carcinomata of her face. These were all excised and she remains well with no apparent metastases 5 years after her initial presentation.

Although patients with multiple tumours are uncommon, recognition of such an occurrence is important to avoid attributing symptoms to metastases from a previously diagnosed tumour. Sequential primary tumours may be amenable to treatment.
\end{abstract}

KEY WORDS: carcinoma breast, carcinoma colon, carcinoma kidney, basal cell carcinoma.

\section{Introduction}

Patients with multiple tumours are uncommon, the reported incidence in tumour patients being $3 \%$ detected clinically and $7.8 \%$ in post mortem studies (Polk, Spratt and Butcher, 1965).

Patients with more than five distinct tumours are rare and on reviewing previous publications we found one patient with six tumours (Taylor and Torrance, 1977), another with seven (Arnot and Borges, 1979) and one with nine (Forrest et al., 1981). It is noteworthy that in these patients the tumours were mainly of gastrointestinal origin. In the case presented here only one of the six tumours arose from the gastrointestinal tract.

\section{Case report}

The patient was 78 years old when she presented in September 1977 with a 2-month history of anorexia and a 1-week history of constipation and lower abdominal colic. She also stated that a lump which had been present in her left breast for more

Correspondence: G. La Ferla, Department of Surgery, Western Infirmary, Glasgow G11 6NT. than 30 years had been increasing in size for 6 months. A biopsy had been performed 30 years previously and she was told that it was an area of fibroadenosis. On examination there was a firm irregular lump $4 \mathrm{~cm}$ in diameter in the left breast. Abdominal examination revealed no abnormality. A barium enema showed an annular stricture of the sigmoid colon. The breast lump was locally excised and was found to be a well-differentiated primary breast adenocarcinoma. Ten days later she had resection of the lesion of the sigmoid colon with end to end anastomosis. There was no obvious intraabdominal spread of tumour. Histologically it was a poorly differentiated primary adenocarcinoma of the colon involving the full thickness of the bowel wall and invading the surrounding fat. The local lymph nodes were not involved.

The patient remained well for 18 months and then complained of dysuria and haematuria. An intravenous urogram showed distortion of the upper calyces of the left kidney.

Nephrectomy was performed in January 1980 and histology showed a well differentiated transitional cell carcinoma of the upper calyces. At about the same time two suspicious skin lesions were excised from her right ear and the bridge of her nose and on histology these were found to be basal cell carcinomata. One month later she found a mass in her right breast and this was locally excised in May 1980. Histologically this was a primary infiltrating duct adenocarcinoma developing in an area of fibroadenosis. The histological appearances were entirely distinct from those of her adenocarcinomata of her left breast and colon.

Her immunological function was normal as expressed by lymphocyte rosette function, transformation by phytohaemagglutinin and pokeweed mitogen and serum immunoglobulins.

She remains well with no clinical or radiological evidence of recurrence of her carcinomata of her left breast, sigmoid colon, left kidney, skin or right breast 5 years after her initial presentation. 


\section{Discussion}

Warren and Gates (1932) outlined the three criteria for the diagnosis of the 'syndrome' of multiple tumours occurring simultaneously or sequentially: the tumour must be malignant, distinct, and not the result of metastases. Their criteria were later endorsed by Moertel, Dockerty and Bagenstross (1966) who have also shown that the risk of developing new malignancies increases with each successive cancer. Indeed patients with cancer of the colon or rectum have a threefold increase in the incidence of metachronous primary cancers of other organs (Schottenfield, Berg and Vitsky, 1969). Three or more tumours are, however, unusual and Mersheimer, Ringel and Eisenberg (1964) confirm this in their study on multiple tumour patients where only $0.07 \%$ had four or more primary cancers. In spite of being rare their behaviour is remarkably similar in different patients, in that they are locally invasive but fail to spread beyond the primary site. The reason for this is not entirely clear but it is known that certain tumours preferentially metastasize to certain sites and, equally, certain sites are particularly resistant to metastasis from different tumours. On this 'soil for seeds hypothesis', it appears that in patients with multiple tumours local tissue conditions are highly unfavourable to metastases, and this accounts for the natural resistance to the spread of primary tumours described by Ostrowski (1975).

Burnet (1971) introduced the idea of a deranged immune surveillance system to explain why some patients have an inherent predisposition to developing multiple tumours. Immune surveillance deals with the specific recognition and destruction of malignant cells. This concept is, however, untenable with the present evidence where common tumours do not occur more commonly in immuno-suppressed patients; laboratory animals devoid of functioning $T$ cells are not especially prone to the development of spontaneous tumours; and that, immune responses can, in certain circumstances, facilitate or stimulate tumour growth (Nelson, 1979). Consequently normal immunological function of the $T$ and $B$ cells do not exclude a possible deranged balance between suppressive and enhancing responses to altered cells which may lead to the emergence of overt neoplasms.

We could find no predisposing cause for our patient's multiple tumours. There was no family or environmental history of any significance was ob- $\_$ tained and the patient has never had radiotherapy of undue exposure to diagnostic $\mathrm{X}$-rays.

With improved methods of diagnosis and the greater longevity of the population more patients with multiple tumours can be expected. Of 20 patients who attend hospital with a malignante tumour, one will later develop another primarye malignant tumour. Follow-up is important ands investigation of new symptoms may demonstrate further tumours. One has to be aware of the risk of attributing symptoms from a new primary tumour tow metastases from a previously diagnosed malignancy as sequential primary tumours may be amenable to surgery.

\section{Acknowledgments}

The authors are most grateful to Mr I. F. Kerr for allowing theno to study his patient.

\section{References}

ARNOT, R.S. \& BORGES, A. (1979) Multiple intestinal malignanc Clinical Oncology, 5, 267.

BURNET, F.M. (1971) Immunological surveillance in neoplasia Transplant Review, 7, 3.

Forrest, J., Slaney, G., Crocker, J., Hallan, J. \& Taylor A.M.R. (1981) Multiple malignancy with a familial tendeney? Clinical Oncology, 7, 357.

MERSheimeR, W.L., RiNGel, A. \& EISEnberg, H. (1964) Someo characteristics of multiple primary cancers. Annals of the New York Academy of Science, 114, 896.

Moertal, C.G., DockerTy, M.B. \& Bagenstross, A.H. (1966) Recent results in cancer research, 7, 191.

NELSON, D.S. (1979) Human tumour immunology. Australian New Zealand Journal of Medicine, 9, 713.

OSTROWSKI, M.J. (1975) Five separate malignancies in one patient? all apparently successfully treated. British Medical Journal, 4, 736.

PolK, H.C., SPRatT, J.S. \& BUTCheR, H.R. (1965) Frequency of multiple primary malignant neoplasms associated with colorectal. carinoma. American Journal of Surgery, 109, 71.

SCHOTTENFIELD, D., BERG, J.B. \& VITSKY, B. (1969) Index of multiple primary cancers: stomach and lower digestive systemJournal of the National Cancer Institute, 43, 78.

TAYLOR, T.V. \& TORRANCE, B. (1977) Behaviour in multiple primary neoplasms. British Medical Journal, 2, 1125.

WARREN, S. \& GATES, O. (1932) Multiple primary malignan tumours: Survey of literature and statistical study. Americaro Journal of Cancer, 16, 1358.

(Accepted 29 September 1983) 